\title{
Comparison of Tweed Facial Triangle Norms Among Different Ethnic Groups
}

\author{
H. A. Hashim, N. AL-Sayed, A. AL-Qaisi, F. A. AL-Jawad, and H. Al-Husain
}

\begin{abstract}
Aims: The objectives of the present study were to establish Tweed facial triangle norms in Qatari and to compare the result with Tweed norms and previous reported results in different racial groups.

Material and method: The sample consisted of 89 lateral cephalometric radiographic radiographs, 75 patients were females and 14 were males with age range 18 to 25 years old (Mean 20.7. +/-2.3).

Results: The result of the present study showed that the mean values of FMA $33.5^{\circ}+/-6.2^{\circ}$ FMIA $52.8^{\circ}+/-9.5^{\circ}$ angles and IMAP $94.5^{\circ}+/-8.8^{\circ}$ were significantly higher than Tweed norms. The comparison with Black Brazilian and Bangladeshi indicated extremely statistically significant differences in FMA and IMPA angles whereas in Nepalese, extremely significant difference was observed in FMIA and FMA angles.

Conclusions: Tweed's Facial Triangle mean values were established for Qatari. However, Tweed facial triangle norms should be used only as a guide and not as an absolute value. Hence, using specific norms for specific race or ethnic group will help in providing more accurate diagnosis and treatment planning.
\end{abstract}

Index Terms - Tweed Facial Triangle norms, Cephalometric analysis, Orthodontics. Lower incisors.

\section{INTRODUCTION}

Cephalometry is mostly used to describe the morphology and growth of the facial skeleton, predict growth, plan treatment and evaluate treatment results. That is by, either digitally or manually, determining the skeletal and dental relationships that exist in an individual patient utilizing selected points in which linear and angular measurements can be used to compare with other reference values between different racial groups. Several analyses were introduced showed variances in different racial and ethnic groups [1]-[8]. Among these, Tweed introduced his own analysis in an attempt to give meaningful relationship between the mandible and the position of the lower incisors which is known by the facial triangle. His measurements were based on four selected cases which he thought they have pleasing facial esthetics and drew the Tweed triangle, which consisted from the Frankfort horizontal plane extended between Prion and Orbitale points (P-Or), the mandibular plane connecting point menton to point Gonion (Men - Go) and the inciso-mandibular plane, by drawing a line through the apex and incisal edge of the mandibular central incisor extending it to intercept the Frankfort Horizontal and mandibular planes. Thus, using these three planes he introduced the diagnostic triangle forming the following angles; Frankfort mandibular incisal

Published on July 21, 2020.

H. A. Hashim, Hamad dental Centre, Qatar.

(corresponding e-mail: hahashim78@yahoo.com).

N. AL-Sayed, Hamad dental Centre, Qatar. angle (FMIA), Frankfort mandibular plane angle (FMA) and third and most important angle is the Incisal mandibular plane angle (IMPA) [3]

In contrast to Downs measurements, Tweed conducted several investigations in his four treated cases samples, 37 sample cases and 95 samples cases and noted that the angle FMIA were close to $65^{\circ}$ with a range of $64.5^{\circ}-66^{\circ}$ and the angle FMA of $25^{\circ}$ with a range of $20^{\circ}-30^{\circ}$ while the normal variation of inclination of mandibular incisor to the mandibular plane IMPA range from $85^{\circ}$ to $95^{\circ}$ with $90^{\circ}$ being considered as norm. He concluded that these norms were workable figures which will result in more ideally proportioned facial esthetic and give stable result. Also, he pointed out without giving the reasons; that the norms used by Downs1 deserve further investigation particularly the normal inclination of mandibular central incisors which he proposes $\left(91.4^{\circ}\right)$ [1], [3]. Furthermore, Tweed highlighted the importance of the angle FMIA of $65^{\circ}$ with respect to treating patients who need either extraction or non-extraction. He stated that in cases having fair facial esthetics and with an FMIA angle less than $57^{\circ}$ or $58^{\circ}$ it is recommended not to rush for extraction of all four first premolars to obtain an FMIA angle of $65 .^{\circ}$ On the other hand, if the facial esthetic is poor, it is advisable and recommended to extract all four first premolars in order to obtain an FMIA angle of $65^{\circ}$ or greater and concluded that perhaps these figures which suggested as norms are not accurate as they might be [3].

In addition to the aforementioned, he proposed that the lower incisors should be vertically positioned on the basal bone (IMPA $90^{\circ}$ ). Hence, to place the lower mandibular incisor in their correct inclination it is deemed necessary to have the aid of the cephalogram. Nevertheless, this confirm the opinion that we should not treat patient according to numbers and visual estimation is not accurate when compared with measurement from lateral skull [3]. After, searching the literature there was no recorded data on Tweed facial triangle norms among the Qatari population. Hence, the aims of this study were to establish Tweed's facial triangle norms and to compare the results with Tweed norms and with other published reports from different racial and ethnic groups.

\section{MATERIAL AND METHOD}

\section{A. Subjects}

The sample consisted of 89 lateral cephalometric radiographs of Qatari patients with mean age of 20.69 \pm 4.9 years (age range of 18-25 years). Seventy-five patients were females and 14 were males. They were selected according to 
the following criteria: skeletal Class I or mild Class II relationship, minor crowding or spacing, no history of orthodontic treatment and no facial deformities and good quality radiograph.

A digital lateral skull radiograph was taken by Planmeca ProMax (84 kV-16mA. Total filtration $2.5 \mathrm{~mm} \mathrm{AI}$ ) manufactured in Finland. The radiograph was taken by welltrained technician at 5 feet's looking straight to her own eyes on the mirror. Each radiograph was hand traced by one operator.

\section{B. Method}

The cephalogram were traced manually in dark room. The following three angles forming the Tweed's facial triangle were drawn and measured to the nearest $0.5^{\circ}$. (Fig. 1). The Frankfort Mandibular plane Angle (FMA), the Frankfort Mandibular Incisal Angle (FMIA), and the Inciso-mandibular Plane Angle (IMPA).

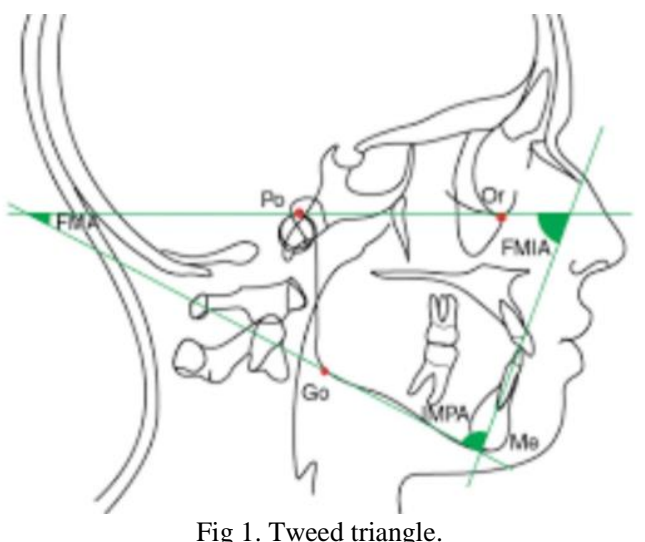

\section{Statistical Analysis}

Data was analyzed using the excel Microsoft program. Descriptive statistics including mean and standard deviation were obtained. For analytical statistics, Student's t-test was used to assess whether there was significant difference between Qatari means values of Tweed's facial angles and Tweed norms as well as comparing difference between both genders and with previous published reports in different racial and ethnic groups. The level of significant was set at $\mathrm{p}<0.05$.

\section{RESULTS}

Out of the 75 females, 34 patients were evaluated as skeletal Class 1 with ANB angle more than zero and less than 3.9 degree and 41 patients as mild skeletal Class II with ANB angle more than 4 degree. In the male sample, 9 males were Class I and 5 were Class II. Ethical approval and consent form were obtained.

The error of the method was assessed by double measurements taken at least one-week interval on five randomly selected cephalograms. The t-test results indicated that there were no statistically significant differences between the two sets of readings.

Table I shows the mean values and standard deviations (SD) of Tweed's facial norms (SD) For Qatari females and males. For females, the angles of FMIA, FMA and IMPA were 52.8+/-6.1, 33.1+/-6.1 and IMPA 94.1+/-6.9; respectively. For males the angles were, 49.8+/-4.8, 33.9+/-
5.0 and 95.1+/-6.9; respectively. There were no statistically significant differences between both genders.

TABLE I: COMPARISON BETWEEN QATARI FEMALES AND MALES

\begin{tabular}{|c|c|c|c|c|c|c|}
\hline \multirow{2}{*}{ VARIABLE } & \multicolumn{2}{|c|}{$\begin{array}{c}\text { Qatari Females } \\
\text { Class I,N=34 }\end{array}$} & \multicolumn{2}{c|}{$\begin{array}{c}\text { Qatari males, } \\
\text { Class I N=9 }\end{array}$} & \multirow{2}{*}{$\begin{array}{c}\text { P- } \\
\text { value }\end{array}$} & $\begin{array}{c}\text { Signifi- } \\
\text { cant }\end{array}$ \\
\cline { 2 - 5 } & Mean & SD & Mean & SD & \\
\hline $\begin{array}{c}\text { FMIA } \\
\text { ANGLE }\end{array}$ & 52.8 & 6.1 & 0.267 & NS & 49.8 & 4.8 \\
\hline $\begin{array}{c}\text { FMA } \\
\text { ANGLE }\end{array}$ & 33.1 & 6.1 & 0.446 & NS & 34.9 & 5.0 \\
\hline $\begin{array}{c}\text { IMPA } \\
\text { ANGLE }\end{array}$ & 94.1 & 6.9 & 0.579 & NS & 95.1 & 6.9 \\
\hline
\end{tabular}

$\mathrm{P}>0.05$ NS. Not significant.

Table II represents the mean values and standard deviation of Tweed facial Triangle in Qatari females as well as for both genders combined, All three angular measurements in the combined sample indicated that the Frankfort-mandibular incisal angle (FMIA), Frankfort Mandibular angle, (FMA) and Inciso-mandibular angle were found to be $50.00^{\circ}, 33.50^{\circ}$, and $94.50^{\circ}$; respectively. No statistically significant differences were noted between the combined sample and the female sample only.

TABLE II: MEAN AND STANDARD DEVIATION OF QATARI FEMALES AND COMBINED BOTH SEXES

\begin{tabular}{|c|c|c|c|c|c|c|}
\hline \multirow{2}{*}{ VARIABLE } & \multicolumn{2}{|c|}{$\begin{array}{c}\text { Qatari } \\
\text { Females } \\
\mathrm{N}=34\end{array}$} & $\begin{array}{c}\text { Mean Qatari } \\
\text { females and } \\
\text { males } \\
\text { combined N= } \\
43\end{array}$ & $\begin{array}{c}\text { P- } \\
\text { value }\end{array}$ & $\begin{array}{c}\text { Signifi- } \\
\text { cance }\end{array}$ \\
\cline { 2 - 6 } & Mean & SD & Mean & SD & & \\
\hline FMIA ANGLE & 52.8 & 6.1 & 52.0 & 8.8 & 0.703 & NS \\
\hline FMA ANGLE & 33.1 & 6.1 & 33.5 & 6.2 & 0.784 & NS \\
\hline IMPA ANGLE & 94.1 & 6.9 & 94.5 & 6.8 & 0.799 & NS \\
\hline
\end{tabular}

Table III. The Angles FMA and IMPA showed no statistically significant differences between Class I and Class II whereas angle FMIA revealed statistically significance difference between both Classes $(\mathrm{P}<0.01)$.

TABLE III: COMPARISON OF THE MEAN VALUES OF THE TWEED'S FACIAL ANGLES BETWEEN CLASS I AND CLASS II GROUPS.

\begin{tabular}{|c|c|c|c|c|}
\hline $\begin{array}{c}\text { Name of the } \\
\text { angle }\end{array}$ & Mean & SD & P-VALUE & Significant \\
\hline FMIA Class I & 52.82 & 9.47 & \multirow{2}{*}{0.0086} & \multirow{2}{*}{$* *$} \\
\hline FMIA Class II & 47.98 & 5.94 & & \\
\hline FMA Class I & 33.09 & 6.49 & \multirow{2}{*}{0.0941} & \multirow{2}{*}{ NS } \\
\hline FMA Class II & 35.49 & 5.75 & & \\
\hline IMPA Class I & 94.09 & 6.86 & \multirow{2}{*}{0.0998} & \multirow{2}{*}{ NS } \\
\hline IMPA Class II & 96.61 & 6.23 & & \\
\hline
\end{tabular}

$\mathrm{P}>0.05$ NS. Not Significant. $\mathrm{P}<0.01 * *$ Very significant.

Table IV indicated that were found in all Tweed's facial triangle norms compared. FMIA mean value was less in Qatari than the value advocated by Tweed whereas the mean values of FMA and IMPA angles were higher than Tweed's norms.

TABLE IV: COMPARISON OF THE MEAN VALUES BETWEEN PRESENT STUDY

\begin{tabular}{|c|c|c|c|c|l|c|}
\hline \multicolumn{1}{|c|}{ AND TWEED'S DIAGNOSTIC FACIAL TRIANGLE NORMS. } \\
\hline Variable & $\begin{array}{c}\text { Mean } \\
\text { Qatari } \\
\text { N=43 }\end{array}$ & $\begin{array}{c}\text { Standard } \\
\text { Deviation } \\
\text { Qatari }\end{array}$ & $\begin{array}{c}\text { Visual } \\
\text { Mean } \\
\text { Tweed } \\
\text { Caucasian }\end{array}$ & $\begin{array}{c}\text { Tweed } \\
\text { Cephalometric } \\
\text { Mean } \\
\text { N }=95\end{array}$ & P-Value & $\begin{array}{c}\text { Signifi- } \\
\text { cance }\end{array}$ \\
\hline $\begin{array}{c}\text { FMIA } \\
\text { angle }\end{array}$ & 52.0 & 8.8 & 65.0 & 68.20 & 0.0001 & $* * *$ \\
\hline
\end{tabular}




\begin{tabular}{|c|c|c|c|c|c|c|}
\hline $\begin{array}{c}\text { FMA } \\
\text { angle }\end{array}$ & 33.5 & 6.8 & 25.0 & 24.57 & 0.0001 & $* * * t$ \\
\hline $\begin{array}{c}\text { IMPA } \\
\text { angle }\end{array}$ & 94.5 & 6.8 & 90.0 & 86.93 & 0.0001 & $* * *$ \\
\hline
\end{tabular}

$\mathrm{P}<0.001^{* * *}$ Extremely Significant.

Table V exhibited comparison between Qatari and Nepalese population sample. There was statistically significant difference in FMIA and FMA Tweed's facial angles where Qatari have higher mean value of FMA angle and less mean value of FMIA angle compared to Nepalese $(\mathrm{P}<0.001)$. IMPA showed no statistically significant difference between Qatari and Nepalese. $(\mathrm{P}>0.05)$.

TABLE V: COMPARISON OF THE MEAN VALUES OF TWEED'S FACIAL NORMS ANGLES BETWEEN QATARI AND NEPALESE.

\begin{tabular}{|c|c|c|c|c|c|c|}
\hline Variable & $\begin{array}{c}\text { Mean } \\
\text { Qatari } \\
\mathrm{N}=43\end{array}$ & $\begin{array}{c}\text { SD } \\
\text { Qatari }\end{array}$ & $\begin{array}{c}\text { Mean } \\
\text { Nepalese } \\
\mathrm{N}=100\end{array}$ & $\begin{array}{c}\text { SD } \\
\text { Nepale }\end{array}$ & P-Value & $\begin{array}{c}\text { Signi- } \\
\text { ficance }\end{array}$ \\
\hline $\begin{array}{c}\text { FMIA } \\
\text { Angle }\end{array}$ & 52.8 & 9.5 & 57.0 & 6.8 & 0.0001 & $* * *$ \\
\hline $\begin{array}{c}\text { FMA } \\
\text { Angle }\end{array}$ & 33.1 & 6.5 & 28.0 & 5.9 & 0.0001 & $* * *$ \\
\hline $\begin{array}{c}\text { IMPA } \\
\text { Angle }\end{array}$ & 94.1 & 6.9 & 95.0 & 5.8 & 0.3265 & NS \\
\hline
\end{tabular}

P $>0.05$ NS Not significant. P<0.001*** Extremely Significant.

Table VI discloses significant differences in FMA and IMPA angles between Qatari and Black Brazilian. On the other hand, no significant difference was noted in FMIA angle.

TABLE VI: COMPARISON OF MEAN VALUES OF TWEED FACIAL TRIANGLE

\begin{tabular}{|c|c|c|c|c|c|c|}
\hline \multicolumn{1}{|c|}{ Variable } & $\begin{array}{c}\text { Mean } \\
\text { Qatari } \\
\text { N=43 }\end{array}$ & $\begin{array}{c}\text { Standard } \\
\text { Deviation } \\
\text { Qatari }\end{array}$ & $\begin{array}{c}\text { Mean } \\
\text { Black } \\
\text { Brazilian } \\
\text { N=37 }\end{array}$ & $\begin{array}{c}\text { Standard } \\
\text { Deviation } \\
\text { Black Brazil }\end{array}$ & $\begin{array}{c}\text { P- } \\
\text { Value }\end{array}$ & $\begin{array}{c}\text { Signifi- } \\
\text { cance }\end{array}$ \\
\hline $\begin{array}{c}\text { FMIA } \\
\text { ANGLE }\end{array}$ & 52.8 & 9.5 & 50.91 & 8.27 & 0.3494 & NS \\
\hline $\begin{array}{c}\text { FMA } \\
\text { ANGLE }\end{array}$ & 33.1 & 6.5 & 20.13 & 6.89 & 0.0001 & $* * *$ \\
\hline $\begin{array}{c}\text { IMPA } \\
\text { ANGLE }\end{array}$ & 94.1 & 6.9 & 99.88 & 4.42 & 0.0001 & $* * *$ \\
\hline
\end{tabular}

P> 0.05 NS Not significant. P<0.001*** Extremely Significant.

Table VII Demonstrated extremely statistically significant differences in FMA and IMPA angles between Qatari and Bangladeshi. No significant difference was noted in FMIA angle.

TABLE VII: COMPARISON OF THE TWEED TRIANGLE MEAN VALUES BETWEEN QATARI AND BANGLADESH.

\begin{tabular}{|c|c|c|c|c|c|c|}
\hline \multicolumn{7}{|c|}{ BETWEEN QATARI AND BANGLADESH. } \\
\hline Variable & $\begin{array}{l}\text { Mean } \\
\text { Qatari } \\
\mathrm{N}=75\end{array}$ & $\begin{array}{c}\text { Qatari } \\
\text { SD }\end{array}$ & $\begin{array}{c}\text { Mean } \\
\text { Bangla- } \\
\text { deshi } \\
\mathrm{N}=89\end{array}$ & $\begin{array}{c}\text { Bangladeshis, } \\
\text { SD }\end{array}$ & $\begin{array}{c}\text { P- } \\
\text { Value }\end{array}$ & $\begin{array}{l}\text { Signifi- } \\
\text { cance }\end{array}$ \\
\hline $\begin{array}{l}\text { FMIA } \\
\text { angle }\end{array}$ & 52.8 & 9.5 & 54.60 & 7.26 & 0.1745 & NS \\
\hline $\begin{array}{l}\text { FMA } \\
\text { angle }\end{array}$ & 33.1 & 6.5 & 24.52 & 5.60 & 0.0001 & $* * *$ \\
\hline $\begin{array}{l}\text { IMPA } \\
\text { angle }\end{array}$ & 94.1 & 6.9 & 100.88 & 6.98 & 0.0001 & $* * *$ \\
\hline
\end{tabular}

P> 0.05. NS: Not Significant. P<0.001*** Extremely Significant.

\section{DISCUSSION}

Several studies reported on the variations between different racial and ethnic groups using the standard cephalometric measurements. The majority of these studies compared Caucasians with non-Caucasians such as;
Japanese, Chinese, Filipino's (Oriental), Africans (Black), and Afro-Americans (Black), and Arabs. Most of the studies indicated that, the Black and the Oriental had the most protrusive dentition and the Caucasians had the most retrusive dentition [9]-[13]. Tweed's Facial Triangle is a method that helps in diagnosis, classification and evaluating prognosis and treatment planning. His conviction is that the acceptance of these figures for FMA, FMIA and IMPA angles will result in a more ideally proportioned facial esthetic and give more stable result. This will be achieved when the lower incisors inclination (IMPA) is at $90^{\circ}+/-5^{\circ}$ vertically positioned on the basal bone [14], [15]. Thus, the determination of the IMPA value is very important for orthodontic treatment planning.

Several investigators reported on the ideal position of the lower incisors in relation to the basal bone. Hasund and Böe [16] introduced a multiple regression equation for the positioning of the lower incisors using floating norms based upon the guiding variables ANB, ML-NL and the $\mathrm{N}$ angle. Mills [17] recommended that the lower incisors should be where they are and considered this is the most stable position since it is in a neutral zone. William [18] on the other hand concluded "no particular method is ideal, the use of Ricketts' A-Po line in giving an indication of permitted direction of movement, tempered by a cautious approach as advocated by Mills should achieve a compromise between improved aesthetics and stability in most cases. A detailed study is required to assess more fully their practical application". Additionally, Ciavarella et al [19] evaluated if changes in lower incisor position following orthodontic treatment are correlated with development of gingival recessions. They found that patients whose lower incisors were excessively proclined $\left(>95^{\circ}\right)$ at the end of orthodontic treatment; developed gingival recession compared to those subjects who had a normal incisor inclination. This finding was not observed in the present study result despite the increased proclination of the lower incisors $\left(95.5^{\circ}+/-6.41^{\circ}\right)$. The result of the present study is not in line with those advocated by Tweed. The mean values of FMA $34.3^{\circ}+/-5.95^{\circ}$ and FMIA $50.3^{\circ}+/-7.63^{\circ}$ angles and IMAP $95.5^{\circ}+/-6.41^{\circ}$ were significantly higher than Tweed facial triangle norms.

Furthermore, the results of the present study when compared with Black Brazilian data indicated extremely statistically significant differences in IMPA angles where Black Brazilians had significant proclined lower incisors. On the other hand, the FMA angle indicated a deep basal configuration opposite to the present study result. No significant difference was noted in FMIA angle.[20]. The results of the present study exhibited extremely statistically significant differences in FMIA and FMA facial angles of the Nepalese when compared to the present Qatari sample. Qataris had higher mean value of FMA angle and less mean value of FMIA. No sextual dimorphism was reported in several studies [20]-[23]. In the present study, although the sample size of the males is small $(\mathrm{N}=14)$, no statistically significant difference was found between both genders. This finding agreed with Bhattarai et al [20] in Nepalese, Kuramae et al [21] among Black Brazilians and Hasan et al [22] in Bangladeshis results. Hence, future studies can be carried out with larger sample size to know the values and differences between both genders that could help in establishing accurate 
orthodontic diagnosis and treatment planning. It is noteworthy to mention that these differences in cephalometric norms among different ethnic and racial groups were reported for each specific group. Thus, care should be taken not to apply those specific norms to another different racial group. Such recommendation was stated by several investigators. [2], [3], [14], [15]. Therefore, using specific norms for specific race or ethnic group will help in providing more accurate diagnosis and treatment planning with the aid of cephalogram [3].

\section{CONCLUSION}

Tweed's Facial Triangle mean values were established for Qatari. However, the present study showed significant differences with Tweed's original values. As a result, Tweed facial triangle norms should be used only as a guide and not as an absolute value. Hence, using specific norms for specific race or ethnic group will help in providing more accurate diagnosis and treatment planning.

\section{ACKNOWLEDGEMENT}

We would like to thank Hamad Medical Corporation/ Hamad Medical Research Center for sponsoring this research (Sub-Research Proposal Number 15041/150). Thanks, and appreciation extended to Dr Hashim AL-Hausain in performing the statistical analysis of the data and Professor Anil Sukumaran for his help in preparing the final proof.

\section{REFERENCES}

[1] Downs, W. Variations in Facial Relationship: Their Significance In Treatment and Prognosis1. Angle Orthod. 19(3): 145-55. 1949.

[2] Steiner, C. C. Cephalometric for you and me." Am J Orthod. 39(10): 729-55. 1953.

[3] Tweed, C. H. The Frankfort-Mandibular Incisor Angle (FMIA) In Orthodontic Diagnosis, Treatment Planning and Prognosis." Angle Orthod. 24(3): 121-69. 1954.

[4] Ricketts, R. M. Cephalometric Analysis and Synthesis." Angle Orthod. 67 (2): 125-38. 1961.

[5] Jacobson, A. The Wits appraisal of jaw disharmony. Am J Orthod. 67(2): 125-38. 1975

[6] McNamara, J. A., Jr. A method of cephalometric evaluation." Am J Orthod. 86(6): 449-69. 1984.

[7] Chan GK. A cephalometric appraisal of the Chinese (Cantonese). Amer J Orthod 61: 279-85. 1972.

[8] Drummond RA. A determination of cephalometric norms for the Negro race. Amer J Orthod 54: 670-82. 1968.

[9] Hideki Ioi, Shunsuke Nakata, Akihiko Nakasima, Amy L CountsComparison of cephalometric norms between Japanese and Caucasian adults in antero-posterior and vertical dimension. Eur $\mathrm{J}$ Orthod. 29:493-9. 2007.

[10] John Wu, Urban Hägg, Bakr A, Rabie M. Chinese norms of McNamara's cephalometric analysis. Angle Orthod;77(1):12-20. 2007.

[11] Emmanuel Olubusayo Ajayi. Cephalometric Norms of Nigerian Children. Am J Orthod Dentofac.Orthop. Nov;128(5):653-6. 2005

[12] Hamdan A. M. Rock W. P. Cephalometric Norms in an Arabic Population. British Orthodontic Society..Vol 28 No. 297-300. 2001.

[13] Marlon Alvaro Moldez. Koshi Sato Junji Sugawara Hideo Mitani. Linear and Angular Filipino Cephalometric Norms According to Age and Sex. Angle Orthod. 76 (5): 800-05. 2006.

[14] Tweed $\mathrm{CH}$. The Frankfort-mandibular plane angle in orthodontic diagnosis, classification, treatment planning, and prognosis. Am J Orthod Oral Surg. 32: 175-232. 1946.

[15] Tweed CH. Was the development of the diagnostic facial triangle as an accurate analysis based on fact or fancy? Am J Orthod. 48: 823-40. 1962.

[16] Hasund A, Böe OE. Angle Floating Norms as Guidance for the Position of the Lower Incisors. Angle Orthod. Jul;50(3):165-8. 1980

[17] Mills, J. R. E. Principles and Practice of Orthodontics.Churchill Livingstone, Edinburgh. 1982.
[18] Williams P. Lower Incisor Position in Treatment Planning. Bri J. of Orthod. Volume 13, - Issue 1. 33-41. 1986.

[19] Domenico Ciavarella, Michele Tepedino, Crescenzio Gallo, Graziano Montaruli, Khrystyna Zhurakivska, Ludovica Coppola, Giuseppe Troiano, Claudio Chimenti, Michele Laurenz, Lucio Lo Russo. Postorthodontic position of lower incisors and gingival recession: A retrospective study. J Clin Exp Dent. 9 (12): e1425-30. 2017.

[20] Bhattarai P. and Shrestha RM. Tweeds analysis of Nepalese people. Nepal Med. Coll. J.13(2): 103-06. 2011.

[21] Mayury Kuramae, Maria Beatriz Borges de Araújo Magnan Darcy Flávio Noue,r Gláucia Maria Bovi Ambrosano, Roger Cristiano Inoue. Analysis of Tweed's Facial Triangle in Black Brazilian youngsters with normal occlusion. Braz J Oral Sci. - Vol. 3 - Number 8. 401-03. 2004.

[22] Hasan Md Rizvi, Md Zakir Hossain. Cephalometric Profile of Bangladeshis: Tweed's Analysis. APOS Trends in Orthodontics, Volume 7 Issue 3. 130-34. 2017.

[23] Bangladeshis: Tweed's Analysis. APOS Trends in Orthodontics, Volume 7 Issue 3. 130-34. 2017.

[24] Insira Sarbeen, Saravana Pandian. Incisor Mandibular Plane Angle (IMPA) in Normo- divergent Individuals. Research J. Pharm. and Tech. 9 (10):1621-22. 2016 